DIGITALCOMMONS @WAYNESTATE-
Michigan Journal of Counseling:

Research, Theory and Practice

Volume 33 | Issue 1

Article 2

8-1-2005

\title{
The Use of Active Group Interventions with Persons with Traumatic Brain Injury
}

Arnold B. Coven

Wayne State University

Katherine G. Van Hull

Wayne State University

Stacey Yaklitch

Wayne State University

Khadija Ali

Wayne State University

Jina Enwiya

Wayne State University

Follow this and additional works at: https://digitalcommons.wayne.edu/mijoc

\section{Recommended Citation}

Coven, A. B., Van Hull, K. G., Yaklitch, S., Ali, K., \& Enwiya, J. (2005). The Use of Active Group Interventions with Persons with Traumatic Brain Injury, Dimensions of Counseling, 33(1), 1-9. doi:10.22237/mijoc/1122854460

This Article is brought to you for free and open access by the Open Access Journals at DigitalCommons@WayneState. It has been accepted for inclusion in Michigan Journal of Counseling: Research, Theory and Practice by an authorized editor of DigitalCommons@WayneState. 


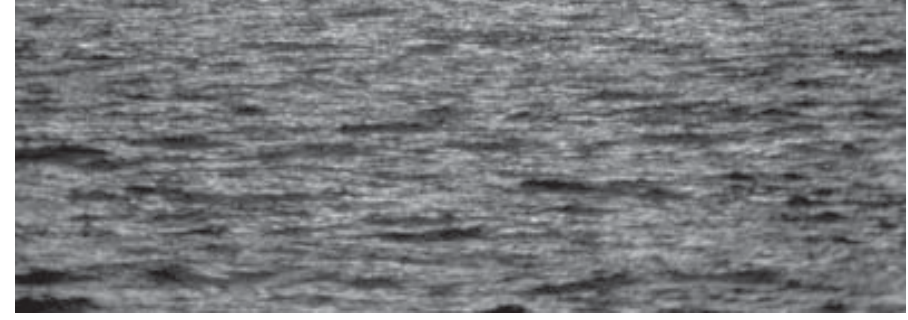

\section{The Use of Active Group Interventions with Persons with Traumatic Brain Injury}

\section{Arnold B. Coven, Katherine G. Van Hull, Stacey Yaklitch, Khadija Ali, and Jina Enwiya}

Wayne State University

Arnold B. Coven is an Associate Professor in the Counselor

Education/Rehabilitation Counseling program at Wayne State

University. Katherine Van Hull is a Senior Lecturer in the

Counselor Education program at Wayne State University. Stacey

Yaklitch is a Cognitive Therapist at the Broe Rehabilitation

Center and a Masters student in Marriage \& Family Psychology

at Wayne State University. Khadija Ali is a Doctoral student in

Counselor Education at Wayne State University. Jina Enwiya is a

Master's student in Counselor Education at Wayne State

University.
Counselors are continually challenged to become more knowledgeable and skilled in assisting persons with disabilities. This article describes group work with persons with Traumatic Brain Injury. Active group interventions were utilized to modify cognitive, affective, and behavioral deficits that affect independent living, vocational adjustment, and interpersonal relationships. The knowledge, skills, and training needed by group counselors in order to use active interventions are identified. The active interventions are discussed in the context of group developmental stages, and key therapeutic factors are illuminated. The experience demonstrated that active group interventions may have potential for persons whose mobility and movement in life have been blocked. 
Corey (2000) and Gladding (2003) point out that group counseling can produce both educational and therapeutic outcomes. Their assumption is that people truly become human through their interactions in groups. Although there is accumulating evidence of the efficacy of group counseling, there is little mention of group counseling for persons with disabilities in several major rehabilitation texts (Gandy, Martin, \& Hardy, 1999; Maki \& Riggar, 1997; Roessler \& Rubin, 1998; Rubin \& Roessler 2001).

However, chapters on TBI are in medical and psychological aspects of disability texts (Rosenthal \& Ricker, 2000; Schwartz, 2002)

A chapter on group counseling with persons with disabilities in a recently published group counseling handbook (DeLucia Waack et. al., 2004), and numerous articles in various journals have appeared on this topic. The Association for Specialists in Group Work (ASGW) devoted an entire journal issue on group counseling with persons with disabilities (1995). Prigatano and Ben-Yishay (1999) indicated that counseling techniques must be modified so that persons with TBI can understand and cope with life in the present. Therefore, the challenge for counselors is to become more knowledgeable and skilled in conducting group counseling with persons with TBI.

The purpose of this article is to explore the use of active interventions in group counseling for persons with TBI by presenting the following: a) The literature describing persons with TBI; $b$ ) the potential of group counseling for persons with disabilities, specifically, TBI; c) training, skills, and guidelines for group leaders; d) active interventions that maximize group counseling for persons with TBI; e) setting, participants, and illustrations of active interventions specific to group stages; and f) discussion, recommendations, and conclusions.

\section{Traumatic Brain Injury}

Traumatic Brain Injury, as defined by the Brain Injury Association, is an insult to the brain caused by external physical force that may produce a diminished state of consciousness, resulting in an impairment of cognitive abilities or physical functioning. Brain injuries result from various causes, including automobile accidents, falls, gunshots, tumors, and strokes. Males aged 14-24 have the highest incidence, due to risk taking behaviors. The chances of a second brain injury are three times greater for persons who have sustained an initial TBI.

Symptoms of brain injury can be highly diffuse. Fontan, Premuda, Lorenzo, and Quintenos (2002) indicate physical, emotional and cognitive changes post TBI. Some of the physical limitations are difficulty in balance, mental and physical fatigue, persistent headaches and pain, weakness or paralysis on one side of the body, impaired or uncontrollable movements, slower motor speed, and in some persons, seizure activity. Symptoms of brain injury can include depression, agitation, impulsivity, fatigue, passivity, difficulties in concentration, or euphoria with a denial of the effects of traumatic brain injury (Schwartz, 2002).

Cognitively, there can be difficulty in focusing attention, a shortened attention span, and memory loss, such as not remembering new information or keeping track of appointments. In addition, there can be a disturbance in spatial orientation, sensory deficits (e.g., neglect of one side of the visual field), and distorted verbal reasoning, causing difficulty in comprehending conversations. Further, disruption in the sense of time, problematic judgment and ability to make decisions, speech and language difficulties, and especially lack of selfawareness can seriously limit activities that have a cognitive component.

Prigatano and Ben-Yishay (1999) indicate that the major problems of persons with TBI are emotional, motivational, and behavioral. Many have suffered a near death experience which threatens their existence and selfworth (Ben-Yishay et al., 1985). Deficits from the brain injury undermine identity and core sense of self, making it difficult to integrate former self-images with the new self (Schwartz, 2002). Persons with TBI frequently experience impairments in: a) social perception; b) selfregulation; c) ability to express empathy; and d) egocentricity (Forsmann-Falck \& Christian, 1989). The cognitive and emotional changes are often invisible to others, whose only indicators of TBI might be any physical changes that occur, but are noticeable to those who have close contact with persons who have TBI (Kay \& Lezak, 1990; Prigatano, 1992). Psychosocially, there can be an exaggeration of pre-injury personality characteristics. A survivor can be ego-centric, experience heightened emotional responses, or flat affect; have decreased frustration tolerance, exaggerated impulsivity, lack of initiative, and a significant percentage develop substance abuse disorders (Kreutzer, Witol, \& Marwitz, 1996). Epidemiological studies of people with head injuries and cognitive impairments have reported continuing psychosocial problems up to 15 years after the TBI (Livingstone, Brooks, \& Bond, 1985).

Kay and Lezak (1990) indicated that limitations are pervasive when there is impaired executive functioning. Frontal lobe damage makes it difficult for individuals to plan and follow through with actions. Further, difficulty in self-monitoring and understanding social situations make them appear unmotivated and disinterested in their vocational rehabilitation and community reintegration. Schwartz (2002) indicated that counseling may not be constructive, because some clients cannot discern pertinent from irrelevant information. Other clients show great insight and understanding, but do not remember 
the content of the sessions immediately after the sessions end, which is a challenge for counselors. Fontan et al. (2002) pointed out that if professionals can identify these residual effects, they can then devise interventions that meet the unique needs of persons with TBI.

\section{Group Counseling for Persons with Disabilities}

Current interest in counseling for persons with illnesses or disabilities has been stimulated by many studies linking psychosocial factors to positive health outcomes of clients who participated in group counseling. Some experts contend that groups are more effective than individual counseling in producing major changes in coping skills and interpersonal relationships. Persons with disabilities, especially those with newly acquired disabilities, have intense concerns regarding their social functioning. Yalom (1995) contends that interpersonal interaction and learning is crucial in group therapy. He indicates that it helps participants to understand what is missing in their interactions with others, which enables them to change. Promoting interaction and feedback between the members are standard group process techniques, even though they are differentiated from action oriented interventions, such as role-play, behavioral rehearsal, and psychodrama.

Seligman and Marshak (2004) indicate that although group issues and some procedures may be typical, some themes are unique to people with disabilities. One concern is whether the acquired disability will be permanent, will improve, or will become worse. Another issue is whether clients can accept their disabilities. Besides the threat to their physical well being, doubts about their continued independence, life control, economic self-sufficiency, and relationships are intensified. The goal of group counseling is to help them face these problems to maintain their identity and stability (Falvo, 1999). Group work also enables persons with TBI to deal with emotional issues, particularly the grief associated with their losses. Typically, emotional needs are overlooked because persons with TBI are sometimes perceived as child-like. They struggle with adult emotions and receive little support from significant others.

\section{Group Leaders: Training, Skills, and Guidelines}

\section{Training and Skills}

Wiener and Oxford (2003) recommend that leaders possess training in psychodynamics, group counseling, and action methods. The first step for leaders is to select members for the group and assess their motivation and commitment for rehabilitation. Pollin (1995) recommends homogeneous groups. When members share a common disability, they experience being an insider with the other members. He suggests that the leader consider the disability type, stage of the disability, condition, age, and gender of the members. Although Pollin recommends embracing homogeneity, Seligman and Marshak (2004) differ, indicating that the personalities of group members are a more critical variable than the disability or stage of rehabilitation.

Stein (1996) indicates a need to modify group counseling techniques for persons with TBI because they experience cognitive and verbal deficits. Seligman and Marshak (2004) identify providing safety as a critical leadership skill due to the traumatic loss experienced by persons who have sustained a brain injury. They also underline the importance of disability knowledge and awareness of the nature of lives of persons with disabilities. Rothenberg (1994) suggests that leaders can promote interaction among the members with TBI by having an individual physically orient toward other group members when they he/she speaking, and then having the other group members echo and repeat back the individual's message. Stein (1996) recommends that the leader summarize regularly and write important themes and messages on the blackboard. Increased structure, along with a problem-solving approach, are needed by those with poor social judgment, and those with TBI who learn concretely. They need help in expressing their perceptions and getting constructive feedback from the other group members. He also recommends regulation of emotional intensity by a graduated, step-like approach.

Wiener and Oxford (2003) contend that counselors can be cross trained to use action methods, thus adding to their repertoire. They indicate that the training is not extensive and can be learned and implemented by group 
counselors. Practitioners educate other mental health professionals, because the timing and sequence of action methods takes practice and experience.

\section{Leader Guidelines}

Before implementing active methods, leaders are advised to create a group atmosphere in which participants feel safe to take risks. Members who are first to volunteer and share may be the most ready to try an active experiment. Their modeling can encourage the other group members to participate. Group interventions that fit specific group stages, as well as the needs and characteristics of group members, are crucial considerations.

Acting and dialoguing with imagined significant others and physically moving in new ways can be threatening to clients. Clients may find these methods strange and demanding. To reduce anxiety, the leaders can limit beginning experiments to visual imagery or just one experimental behavior before more involved role-play. For example, a group member who states, "I feel tied up in knots" can be encouraged to assume a knot-like physical position (Coven, Ellington, \& Van Hull, 1996). The group leader does not know beforehand what will happen when members are asked to role-play. The expectancy has to be open enough to allow expression of the response that emerges (Coven et al., 1977), and the leader must be careful not to judge clients' enactment as right or wrong.

Another guideline is to observe and listen for feelings, thoughts and behaviors that can be enacted. Phrases and metaphors like "I am burdened in life" or "I feel like I have two left feet" have the potential to be acted out. An additional principle is to create physical action and movement. The use of props and room furnishings, like chairs and cushions, can add to the behavioral reality and establish the mood for staging and acting. Room rearrangements help clients learn that it is possible to change the environment to meet one's needs. The group leader can develop the model of how to help members talk about events in the "here and now" (i.e., asking an employer for a job). Members are requested to play the roles as if they are actually happening now to experience the feelings that accompany immediacy. The acting and physical movement can facilitate group members becoming more active in their rehabilitation effort. Another guideline is for members to imagine persons doing an experiment that is opposite to their typical behavior. This approach highlights humans' polar and contradictory tendencies. These active interventions challenge the person to behave in a manner that is new and alters an existing self-perception.

\section{Active Group Interventions}

Wiener and Oxford (2003) describe active methods as experiential techniques using physical movement, dramatic expression, and role play that group members engage in with direction from the group leader and group participants. Kipper (1994) believe that active methods approaches of psychodrama, role play, and behavioral rehearsal incorporate counseling activities that emphasize specific, tangible experiences as the basis of interventions. Zinker (1971) postulates that acting well is a rehearsal for living well, and involves the thinking, feeling, and behavior of group members. The assumption is that learning and behavior modification take place more rapidly when the whole person (muscular, sensory, body activity) is involved. Action methods differ from experiential psychotherapy, which typically refers to methods that focus attention and awareness in the "here and now" but do not necessarily involve the physical activity of action methods. The physical movement can mobilize energy, increase excitement, and promote risk taking of group members, reducing their habitual behavior and responses.

Active group counseling methods can help members move from comfortable and familiar behavior to novel ways of interacting and behaving. As a result, new skills, competencies and action insights can be developed (Moreno, 1969). One major advantage of action methods is the engagement of clients who mostly process visually or kinesthetically. The interventions can reduce the emphasis on verbal and intellectual ability, and provide the opportunity to use one's senses. Wiener and Marshak (2003) hypothesize that action methods may facilitate the resolution of psychological trauma and decrease the performance anxiety typically experienced by persons who have sustained a TBI. Operating less at a cognitive level can reduce habitual defenses against the anxiety produced by their impairments. Action techniques can dramatize role relationships and perceptions of others and can lead to new ways of interacting in the safe, supportive group environment. Many counselors believe role-play and practice in group counseling can help a client generalize new behaviors to life in their environment. Thus, active group interventions may have the potential to enable persons with TBI to learn how to modify their behavior and achieve the rehabilitation goals of employment, independent living, and community integration.

Quantitative research substantiating the use of action methods is limited. Even less empirical evidence applying these methods to special populations exists. On the other hand, many case studies and qualitative research have supported the value of action methods (Wiener \& Oxford, 2003). The counseling community generally accepts that verbal psychotherapy is not 
substantially effective with certain populations. This implies that action methods have some merit and warrant further investigation.

\section{Setting, Participants, and Active Group Methods Specific to Group Stages}

\section{Setting and Participants}

The participants were outpatients or lived in residencies provided by a rehabilitation center located in Metropolitan Detroit, which provides case and medical management, life care planning, cognitive therapy, and vocational rehabilitation services. The case managers were informed that the group counseling focus would emphasize coping skills, socialization, and vocational issues. They identified 20 clients who might benefit from working on these objectives. Additional criteria were general functioning and ability to relate interpersonally. If the case managers believed the clients would be disruptive, they were rejected as participants. The group leader accepted the case managers' screening judgments. The participants were divided into two groups of 10 each, and 10 sessions were conducted with each group. The male leader, who had 30 years of individual and group counseling experience, was assisted by a female co-leader for each group. One co-leader was a cognitive therapist staff member in the center who had an undergraduate degree in psychology but lacked experience in group counseling. The second co-leader was a doctoral student from the counselor education and rehabilitation counseling department who had group leader experience.

\section{Stages and Illustrations}

Groups typically go through four or five developmental stages (Gladding, 2003): Beginning, transitional, working, and termination. For all of the stages, group process has been defined as the interactions of group members as the group develops. Yalom (1995) indicates that process refers to the nature of the relationships between interacting individuals. He identifies 11 factors that are therapeutic in group counseling. Seligman and Marshak (2004) emphasize five of Yalom's therapeutic factors that could be effective with persons with disabilities: a) imparting of information - members and leader sharing information about needed services; $b$ ) instillation of hope - members receiving encouragement and recognition for progress from group members; c) universality - members' similarities connect them to one another; they are connected and do not need to define existence by their disability; d) altruism - the effort of group members to increase each others' self-esteem; and e) socialization skills- the interaction of members promoting the development of interpersonal skills.

\section{Beginning Stage}

The leader began the first session by inviting members to share names or nicknames. The members were encouraged to use the pronoun " $\mathrm{I}$ " and look and speak directly to the other participants. After a few members had introduced themselves, the leader instructed them to repeat the name of those who had already volunteered. This activity reinforced members' identity and sense of belonging and stimulated interactive functioning (Ben-Yishay et al., 1985). The leader cued the members to use "I" by pointing to his chest. To foster eye contact and direct communication between members, the leader moved his arm in a circular fashion in the direction of all the group members (the name of members have been changed to guarantee anonymity of the participants).

Ivy $^{1}$ sat apart from the circle, averted her eyes and did not volunteer. She appeared depressed and distant. When her turn came to introduce herself, she talked proudly about her past job as a flight attendant. As she spoke, her demeanor changed. She became quite animated, and her mood visibly improved. Despite her engagement in this session, she missed subsequent sessions and eventually dropped out. Frank, of Arabic background, was perceived as resistant by the female staff, but was noticeably more self-disclosing to the male leader, which underlines the importance of shared gender leadership. Males who have sustained a disability may perceive their masculinity to be threatened, and can often be defensive with females. It was surprising that Art, who generally isolated himself from everyone else, attended the session. The day before, he had refused to participate, despite substantial encouragement from his case manager.

In summary, members generally shared more information than their names, especially sharing how they sustained their traumatic brain injury. It was interesting that their comments focused on how they functioned before the accident. This could be reflective of the difficult transition they were facing in life.

The participants talked about their general life goals, such as getting a job. One wanted carpentry training, another aspired to become a medical transcriber, and another wanted a job at the rehabilitation center. Several were 
unclear about their goals. They tended to be tentative, using the word "maybe," and dwelled on the past. This lack of clarity is typical of the beginning group stage, regardless of whether the members have disabilities. The members expressed lack of confidence in their ability to succeed, which seemed to be the basis for their hesitancy in choosing vocational goals. Several participants recognized that they were unable to return to their previous jobs due to memory, attention, and visual hand coordination difficulties. All of these factors contributed to their uncertainty about present vocational capabilities.

Art attempted to return to printing but failed and nearly injured himself again. Encouraged to continue disclosing, he remembered his successes as a silkscreen printer. Unfortunately his employer went out of business. The leaders emphasized his success.

Common feelings expressed in the beginning stage were depression, sadness, and loss. Ruth especially missed being independent and having control of her life. Her open acknowledgment of loss was contagious as others expressed what they now missed in life. Rachel, a supportive member, expressed that Ruth would tire of crying and would move on with her life. Ruth's difficulty reflected the struggle she and other trainees face to develop a new self-identity and meaning in life. Another group theme was the desire to help each other, which reduced their focus on personal problems. The leaders facilitated intrapersonal and interpersonal sharing to maximize altruism and universality.

\section{Transition Stage}

During these sessions, a few members were so sleepy that it was difficult for them to participate and interact in the group. Two members, who exercised daily, advocated that other members visit the nearby fitness center. Although the suggestion was presented in dogmatic fashion, the members seemed open to more physical activity. They liked the leader's suggestion of having an exercise group at the beginning of the day and after lunch. This stimulated one of the first active interventions. The leader encouraged the members to move their legs, accelerate the movement, and loudly voice the phrase "I have to get moving in life." The experiment was concluded by standing and cheering for themselves using their first names. This appeared to mobilize their energy and lift their mood, and underlined the approach of doing the exercise in the here and now, instead of just talking about the fatigue problem. The phrase "... moving in life" supported movement toward the rehabilitation goal. The self-cheering reinforced the need to emotionally support themselves. Despite the surge of increased energy and hope, several members continued to be absent from group meetings.
Several group members perceived the medical staff acting as if they did not exist. The medical staff talking directly to the case manager and ignoring the members fostered this perception. The expression of resentment was universal, had cathartic effects, and highlighted the group's growing cohesiveness, a key group therapeutic factor. Members also questioned the leader's motivation. Their trust was somewhat increased when the leader revealed a lack of monetary compensation but a strong desire to learn and share his knowledge. Distrust, resistance, and lethargy are typical reactions of persons with TBI, and of the transitional stage in group counseling (Ben-Yishay et. al., 1985). It is imperative that the leaders remain non-defensive during this "storming" characteristic of the transition stage.

\section{Working Stage}

The members were asked to give each other feedback during the working stage. Group experts emphasize how feedback contributes to intrapersonal and interpersonal learning, two additional therapeutic factors identified by Yalom (1995). Positive feedback was shared between two group members who noted each other's progress. John told George that he enjoyed their friendly conversations as roommates, which reflected George's increased sociability. Rachel confronted Errol with her perception that he coasted through life and had the potential to achieve a great deal more. Unfortunately, the challenge and support did not motivate him to seek employment. Ronald appreciated the wisdom of his older roommate, and one participant remarked about a member's "breaking out of his shyness." The co-leaders highlighted the progress they observed in the members. These examples illustrated instillation of hope and altruism.

As the sessions progressed, the active counseling techniques of role play and psychodrama were introduced. Rachel stated she was regressing. She felt trapped in a closet, which confused her. She was willing to do an acting experiment. First, she walked backwards to depict her regression. She then demonstrated where she started at the beginning of her rehabilitation. Next, she walked forward to show the progress she had made, becoming aware that she had not regressed as much as she feared. To portray being in a closet, she placed herself in a corner of the room not visible to the group. She immediately came out, and realized she would not accept being invisible. In the last part of the experiment, she shared one thing she was clear about to each group member. The verbalization of clarity reduced her confusion and frustration, leading to the insight that she had made progress. She was now more motivated to overcome her struggles. Regrettably, the insurance company reduced her benefits, and she was only able to attend the rehabilitation center one day a week. This 
environmental reality factor reduced her hope and may have increased member distrust of the rehabilitation staff. She chose the day she could continue to participate in the group.

Jim talked and walked slowly. He showed the group how his left hand and leg were shorter, and contracted, interfering with his dexterity and mobility. The leader, using the Gestalt concept of opposites, asked him to walk at his usual slow gait, and then experiment with walking as fast as he could. The group was amazed at his speed and force in covering the distance in the room. He resembled a speed walker as he triumphantly smiled at the group. The leader suggested that his leg power and energy might have vocational potential, thus emphasizing a new side of his physical self, while simultaneously increasing his selfesteem.

Joe talked about how his life was rapidly snowballing. The snowball was becoming larger, and it represented anger, frustration and confusion. The leader instructed him to imitate the snowball by moving his arms in a rolling fashion with increasing speed. He was able to share with the group one thing that was upsetting and confusing him. The physical movement and verbalization released anger, and increased awareness of being hurt by others. He connected it to being adopted and physically and emotionally abused as a child. Although he was unable to reach out and touch others, he was receptive to group members hugging him. The experiment highlighted the closeness he desperately sought. The group stayed focused on him during this emotional struggle, demonstrating the power of interpersonal interaction and the learning that occurs in a psychodrama.

Throughout the working stage, common themes surfaced. The group members explored their barriers to employment. Several had lost their driver's licenses or did not have an automobile. Lou was afraid to drive, and Sarah questioned her driving judgment, since she had 10 accidents after her TBI. A few had pending lawsuits and perceived work as threatening their financial settlement. Sarah wanted to work but was fearful of losing Medicaid insurance, which financed her $\$ 2,000$ monthly medication costs. Several expressed appreciation for their rehabilitation center placement, which helped them avoid relapsing into substance abuse.
The leader noticed that attendance was substantially decreasing in one group and minimally in the second. Several members, with their case manager's assistance, had arranged conflicting appointments with doctors or other therapists. Others were ill or did not show up. In an attempt to identify the reasons for the decrease in attendance and interest, the leader consulted with the staff co-therapist who indicated treatment and training occurred on two different weekdays. Members were reluctant to come to the rehabilitation center an additional day for group counseling. Prigatano and Ben-Yishay (1999) have indicated that persons with TBI typically do not engage in physical, occupational, language therapy or treatment programs aimed at independence and work entry. This reflects the motivational issues that the literature indicates are typical of persons with TBI. Also, the absenteeism may have related to the case managers not understanding the group counseling program. The leader failed to consult with the case managers, a critical component for collaborative treatment in a rehabilitation center.

\section{Closing Stage}

During this stage, some participants spontaneously focused on family relationships before and after their accidents. Errol's father abandoned the family and his mother had to care for the seven children. A child assaulted him with a baseball bat in the third grade resulting in his TBI. He eventually abused drugs and alcohol, was placed in several mental hospitals and spent 10 years in jail. He now was interested in janitorial training, and the leader was able to arrange an appropriate referral. Again, he did not follow up on this opportunity.

George's family had been too busy to give him attention and only now recognized him as a person with a disability. Rachel's family moved 27 times. Her mother said she hated her; therefore, she felt ugly and unloved. In a role play experiment, she now responded to her mother with "that's your problem." She no longer tolerated abuse and had learned to stand up for herself. The guideline for the leader's experiment was to give Rachel an opportunity to empower herself in the present. This role play demonstrated Rachel's recapitulation of early family life, another key group therapeutic factor. 
During these closing sessions, the leaders were able to give several members positive feedback. Ruth and Ed were praised for their intelligence and verbal fluency. John received recognition for his life and work energy. Lastly, Rachel was commended for her supportive and giving nature. The participants also gave each other feedback and encouragement, especially to Ruth, who mourned her past life. They highlighted her willingness to provide assistance and hope to others.

There was a dramatic change in Art, who said he was waiting to die. He did not venture out and lived like a recluse, due to discomfort with his facial disfigurement. He agreed to receive feedback from the group about his physical appearance. Most thought he had a pleasant face despite his missing eye and small facial disalignment. He verbalized not believing the feedback, but his smile was not congruent. Art concluded the feedback experiment by sharing his positive characteristic of liking people, a sharp contrast to not having an interest in life. The feedback provided the opposing perception, challenged Art's rigid self-view, and increased his appreciation for others. A dramatic discovery was that despite their depression, several believed their accident had helped them become more motivated and caring persons than before the TBI. This may have related to the bonding and support of the group members and the creation of a family atmosphere by the rehabilitation staff.

\section{Recommendations}

The need of members to help others seemed related to their near death experiences and subsequent disability, since their appreciation for life and others came up repeatedly in the group sessions. It is recommended that the leader allow the members to respond to each others' sharing of life and problems to maximize altruism and hope. This can strengthen the members' power to be therapeutic and can increase their self-esteem and interpersonal effectiveness. The issues of the members' motivation, low energy, and fatigue seemed intertwined. It was distressing for the leaders when one or two members seemed to be sleeping during the group sessions. Attempts to mobilize energy by increased physical activity did not overcome the lethargy. Daily exercise at the center might help, along with increased center activities. Further, assisting the members to set daily goals might increase motivation. Another technique is for program graduates to visit and share their success. The leader read a story of a successful rehabilitation of a war hero who had sustained a TBI. He was immobilized for two years until he entered a rehabilitation center where psychodrama enabled him to express anger and hurt at his fiancÈ who had abandoned him (Prigatano \& Ben-Yishay, 1999). Successful models and bibliotherapy techniques may increase the instillation of hope while promoting the use of psychodrama with group members.
Another potentially helpful technique is to conduct the group sessions in job settings, which could reduce the fear of employment.

The previous exploration of the use of action oriented methods in group counseling for persons with TBI helps show the need for group leaders working with this population to obtain knowledge and understanding of the lives and challenges faced by persons with disabilities. These group examples are congruent with experts' views that leaders need to create a safe environment and remain patient in the face of the slow progress, lack of attendance, and seemingly weak motivation of group members with TBI.

The high incidence of absenteeism, fatigue, and slow movement in achieving employment and vocational direction appeared to reflect a lack of engagement in the group process and with the leaders. In retrospect, the group leaders could have arranged individual interviews before the beginning of group sessions. This may have developed stronger relationships with the leaders, which may have increased the engagement of group members and consistent group participation. The action methods and group therapeutic factors appeared to have an impact on but did not increase attendance, engagement, or goal attainment. Ten sessions seemed to be insufficient for persons with TBI, whom experts indicate have persistent social, emotional, and employment difficulties. The promising response by some group members to active interventions underlines the need for empirical testing for the effectiveness of action methods on persons with TBI and other disabilities.

\section{References}

Association for Specialists in Group Work. (1995). Special issue on group counseling with persons with disabilities. Journal for Specialists in Group Work, 20, 2.

Ben-Yishay, Y., Rattock, J., Lakin, P., Piasetsky, E., Ross, B., Silver, S.L., et al. (1985). Neuropsychological rehabilitation: The quest for a holistic approach. Seminars in Neurology, 5, 252-259.

Corey, G. (2000). Theory and practice of group counseling ( $5^{\text {th }}$ ed.). Pacific Grove, CA: Sage.

Coven, A.B. (1977). Using Gestalt psychodrama experiments in rehabilitation counseling. Personnel and Guidance Journal, 56, 143-147.

Coven, A.B., Ellington, D.B., \& Van Hull, K.G. (1996). The use of Gestalt psychodrama in group counseling. In S. Gladding (Ed.), Cass Capsules: New developments in group counseling. Greensboro, N. Carolina: ERIC.

DeLucia-Waack, J.L., Gerrity, D.A., Kalodner, C.R., \& Riva, M.T. (Eds.) (2004). Group Counseling and Psychotherapy. Thousand Oaks, California: Sage.

Falvo, D.R. (1999). Medical and psychosocial aspects of chronic illness and disability. Gaithersburg, MD: Aspen

Fontan, L., Premuda, P., Lorenzo, J., \& Quintenos, M. (2002). Comparing brain injury rehabilitation practices: What can North and South Americans learn from each other. Journal of Rehabilitation, 68, 20-25.

Forsmann-Falck, R., \& Christian, F.M. (1989). The use of group therapy as a treatment modality for behavioral change following head injury. 
Psychiatric Medicine, 7, 43-50.

Gandy, G. L., Martin, E. D., \& Hardy, R. E. (Eds.) (1999). Counseling in the Rehabilitation Process. Springfield, Illinois: Thomas.

Gladding, S. (2003). Group work: A counseling specialty (4 ${ }^{\text {th }}$ ed.).Upper Saddle River, N.J.: Merrill Prentice Hall.

Kay, S., \& Lezak, M. D. (1990). The nature of head injury. In Traumatic Brain Injury and Vocational Rehabilitation. Stout, WI: University of Wisconsin-Stout.

Kipper, D. A. (1994). Considering psychotherapy supervisor development: A status report. Psychotherapy Bulletin, 29, 15-19.

Kruetzer, J.S., Witol, A.D., \& Marwitz, J.H. (1996). Alcohol and drug use among young persons with traumatic brain injury. Journal of Learning Disabilities, 29(6), 643-651.

Livingston, M.G., Brooks, D.N., \& Bond, M.R. (1985). Patient outcome in the year following severe head injury and relative psychiatric and social functioning. Journal of Neurology, Neurosurgery and Psychiatry, 48, 876-881.

Maki, D. R., \& Riggar, T. F. (Eds.) (1997). Rehabilitation counseling: Profession and practice. New York: Springer.

Moreno, J.L. (1969). Psychodrama (Vol.3). Beacon, N.Y.: Beacon Press.

National Institute of Health. (1998). Rehabilitation of persons with traumatic brain injury.

NIH Consensus Statement Online 1998, October 26-28 (On-Line). Available: http: / / odp.od.nih.gov/ consensus/ cons/109/109statement.htm/

Pollin, I. (1995). Medical crisis counseling. New York: Norton.

Prigatano, G. (1992). Personality disturbances associated with traumatic brain injury. Journal of Consulting and Clinical Psychology, 60, 360-368.

Prigatano, G., \& Ben-Yishay, Y. (1999). Psychotherapy and psychotherapeutic interventions in brain injury rehabilitation. In N.M. Rosenthal (Ed.), Rehabilitation of the adult and child with traumatic brain injury ( ${ }^{\text {rd }}$ ed., pp. 271-283). Philadelphia: Davis.

Roessler, R. J., \& Rubin, S. E. (1998). Case management and rehabilitation counseling: Procedures and techniques ( $3^{\text {rd }}$ ed.). Austin, TX: Pro-Ed.
Rosenthal, M., \& Ricker, J. (2000). Traumatic brain injury. In R.C. Frank \& F. Elliot (Eds.), Handbook of rehabilitation psychology (pp. 4974). Washington, D.C.: American Psychological Association.

Rothenberg, E.D. (1994). Bereavement interventions with vulnerable populations. Social work with Groups, 17, 61-75.

Rubin, S. E., \& Roessler, R. T. (2001). Foundations of the vocational rehabilitation process. Austin, TX: Pro-Ed.

Schwartz, S. H. (2002). Traumatic Brain Injury. In M.C. Brodwin, F. Tellez \& M.S. Brodwin (Eds.), Medical, psychosocial and vocational aspects of disability (pp. 363-373). Athens, GA: Elliot \& Fitzpatrick.

Seligman, M., \& Marshak, L. (2004). Group approaches for persons with disabilities. In J.L. Delucia-Waack, D.A. Gerrity, C.R. Kalooner, M.T. Riva (Eds.) Group Counseling and Psychotherapy (pp. 239-252). Thousand Oaks, Calif: Sage.

Spira, J.L. (1997). Group therapy for medically ill patients. New York: Guilford.

Stein, S.M. (1996). Group psychotherapy and patients with cognitive impairment. Journal of Developmental and Physical Disabilities, 8, 263-273.

Wiener, D.J., \& Oxford, L.K. (Eds.) (2003). Action therapy with families and groups. Washington, D.C.: American Psychological Association.

Yalom, I. (1995). The theory and practice of group psychotherapy. New York: Basic Books.

Zinker, J. C. (1971). Dreamwork as theatre. Journal of the American Academy of Psychotherapists, 1, 33-37.

\section{Footnotes}

${ }^{1}$ Names of the participants have been changed to ensure anonymity and confidentiality. Written and verbal permission was obtained to use the individual and group illustrations. 